\title{
La feria como espacio político: el caso de la Feria del Libro de Frankfurt de 1976 como plataforma de denuncia de las dictaduras del Cono Sur
}

\author{
Carmen Moreno Mínguez ${ }^{1}$
}

Recibido: 15 de marzo de 2018 / Aceptado: 25 de septiembre de 2019

Resumen. En este estudio de caso sobre la Feria del Libro de Frankfurt de 1976, dedicada a la literatura latinoamericana, quiero analizar de qué manera las ferias del libro pueden articularse como espacios de discurso y acción política. En el contexto de los movimientos de solidaridad con el Cono Sur que emergieron en Europa tras el golpe de estado de Pinochet en Chile en 1973, me interesa examinar cómo los ámbitos culturales, en general, y la escena literaria, en particular, se conformaron como plataformas de denuncia de los regímenes dictatoriales latinoamericanos. En el caso de la Feria del Libro de Frankfurt de 1976, quiero indagar en los agentes y en los discursos que transforman el escenario literario y editorial en un espacio político.

Palabras clave: espacio literario; feria del libro; performance política; discurso político; movimientos de solidaridad; prácticas culturales; espacios transnacionales

\section{The fair as a political space: the case of the Frankfurt Book Fair of 1976 as a platform against the dictatorships of the Southern Cone}

\begin{abstract}
In this case study on the Frankfurt Book Fair of 1976, that had Latin-American literature as its honour guest, I want to analyse how book fairs can act as spaces for political action and political discourses. In the context of the emergence of solidarity movements with the Southern Cone after Pinochet"s military coup in Chile in 1973, I will try to examine how cultural activities in general, and the literary field particularly, served as platforms to condemn the Latin-American military regimes. In the case of the Frankfurt Book Fair of 1976, I want to enquire into the agents and the discourses that transformed that literary sphere into a political space.
\end{abstract}

Keywords: literary space; book fair; political performance; political discourse; solidarity movements; cultural practices; transnational spaces

Sumario. 1. La feria del libro de Frankfurt en el marco de los movimientos de solidaridad con el Cono Sur: un enfoque transnacional 2. Retrospectiva: la politización de la feria del libro de Frankfurt desde finales de los sesenta. 3. América Latina: un continente literario desconocido. 4. La politización de la feria del libro de 1976: Voces por el Cono Sur. 5. Conclusiones. 6. Referencias bibliográficas y fuentes.

Cómo citar: Moreno Mínguez, C. (2019). "La feria como espacio político: el caso de la Feria del Libro de Frankfurt de 1976 como plataforma de denuncia de las dictaduras del Cono Sur". Cuadernos de Historia Contemporánea, Vol. 41: 69-87.

\footnotetext{
1 Johann Wolfgang Goethe-Universität Frankfurt am Main

E-mail: cmorenominguez@gmail.com
} 
“(...) Porque no es la reunión misma la que tiene importancia sino su irradiación hacia una América Latina profundamente solitaria, la de millones de hombres para los cuales no hay reuniones, no hay libros, no hay puentes".

Julio Cortázar

\section{La feria del libro de Frankfurt en el marco de los movimientos de solidaridad con el Cono Sur: un enfoque transnacional.}

En abril de 2015, el escritor y periodista español Ricardo Bada publicaba un artículo en homenaje al recién fallecido escritor uruguayo Eduardo Galeano. Tras emigrar a Alemania en 1963, Bada había desarrollado su carrera periodística como redactor en la emisora de radio alemana Deutsche Welle. En ese artículo publicado en abril de 2015, recordaba cómo había conocido al escritor uruguayo en septiembre de 1976, a lo largo de un coloquio de escritores latinoamericanos y alemanes que se celebró en Sprendlingen en el marco de la feria del libro de Frankfurt de aquel año, dedicada a la literatura latinoamericana. Bada contaba que a través de la invitación, "Eduardo y Helena, su esposa, habían logrado escapar de Argentina, donde él dirigía la redacción de la revista Crisis y estaba amenazado de muerte por la AAA, de lúgubre recuerdo."2 Varios medios alemanes criticaron en esos días la alta politización de los debates literarios en las sesiones del coloquio. El propio Bada cuenta en su artículo como "en aquellas noches de Sprendlingen, durante las pausas y a renglón seguido de las ponencias y debates, platicamos todo lo platicable acerca de la situación y de las posibles salidas a ella"3. El coloquio supuso el comienzo de la relación entre ambos escritores y, terminada la feria del libro, Galeano y su mujer permanecieron cerca de un mes - las primeras semanas de su exilio- en casa de Bada y su familia, antes de partir para establecerse en Barcelona.

Esta reunión de escritores que se celebró en Sprendlingen en septiembre de 1976, unos días antes de la inauguración de la feria, da testigo de la presencia que los debates políticos en torno a la situación de los países latinoamericanos, y en especial del Cono Sur, tuvieron en el contexto de un evento literario y editorial como era la feria del libro de Frankfurt.

Durante la década de los setenta la problemática política latinoamericana había adquirido un creciente protagonismo en Europa Occidental. El golpe de estado de Pinochet en Chile contra el gobierno democrático de Salvador Allende y la Unidad Popular, la instauración de una dictadura militar en el país y el desencadenamiento de persecuciones, detenciones y torturas por parte del nuevo régimen tuvieron una gran resonancia mediática en Europa. Las protestas iniciales fueron cristalizando en forma de movimientos de solidaridad inéditos en el continente y que tuvieron como principal protagonista a la sociedad civil. En los últimos años, han aparecido una serie de estudios que abordan el desarrollo de los movimientos de solidaridad con Chile y con el Cono Sur en estos años y las múltiples formas en que estos adquirie-

Bada, R.: https://www.nexos.com.mx/?p=24648 Consultado el 08.03.2018

Bada, R.: https://www.nexos.com.mx/?p=24648 Consultado el 08.03.2018 
ron: campañas informativas y de recaudación de fondos, protestas, publicaciones o formación de asociaciones ${ }^{4}$.

Entre los diferentes aspectos de los movimientos de solidaridad europeos, trabajos recientes han puesto el foco en el papel que las prácticas culturales tuvieron como plataformas de popularización de las reivindicaciones de esos movimientos. Al hablar de prácticas culturales me refiero a actividades específicas llevadas a cabo por los participantes en los movimientos de solidaridad en el ámbito de la cultura. Cultura, ese término en constante debate, adopta aquí una de las definiciones propuestas por Christopher Endy: "it refers to the creative output of artists, musicians, writers, filmmakers, and others engaged in arts and entertainment's. En la introducción a la obra colectiva European Solidarity with Chile, que analiza el fenómeno de la solidaridad a través de casos nacionales y locales a escala europea, los autores reflexionan sobre el papel de estas actividades culturales. Plantean, por ejemplo, que la poesía de Pablo Neruda, referente internacional de la Unidad Popular chilena, fue un reclamo clave en los discursos de los exiliados para atraer la atención de las sociedades europeas hacia la causa democrática chilena: "During the 1978 Madrid conference, staged with the World Peace Council by Chile Democrático and other Unidad Popular parties in exile, the poetry and memory of Pablo Neruda were almost as prominent on the agenda as the struggle inside in Chile, which remained hampered by effective repression and continuing polarization among Chilean exiles".

En esta línea, analizar el rol de las prácticas culturales asociadas a los movimientos de solidaridad resulta esencial para comprender la enorme dimensión que estos adquirieron en los setenta. Fragmentos como el anterior señalan que las iniciativas culturales jugaron un papel importante en la popularización y propagación de reivindicaciones políticas y en la creación de vínculos entre aquellos que participaban. Precisamente también desde la perspectiva de la Historia de las emociones, las prácticas culturales constituyen un caso de gran interés por su carácter interactivo y por el despliegue emocional que se genera en conciertos, lecturas y otras actividades donde las sociedades europeas entran en contacto con la realidad de los perseguidos por los regímenes militares latinoamericanos.

La mayoría de los estudios que han abordado la dimensión cultural de los movimientos de solidaridad con Chile y con el Cono Sur se han centrado en el caso de la música $\mathrm{y}$, especialmente, en el rol de grupos latinoamericanos en el exilio -el caso más famoso lo constituye la agrupación chilena Quilapayún-. Objeto de estos estudios ha sido la forma en que, a través de sus conciertos, los grupos musicales colabo-

4 Algunas de estas obras son: Christiaens, K., Goddeeris, I., Rodríguez, M. (eds.) (2014). European Solidarity with Chile 1970s-1980s, Frankfurt am Main, Peter Lang; Becker, J., Eckert, J., Kohli, M., Streeck, W. (Eds.) (2004). Transnationale Solidarität. Chancen und Grenzen, Campus Verlag, Frankfurt am Main; Hensel, S., Rommé, B., Rupflin, B. (Eds.) (2011). Chile Solidarität in Münster. Für die Opfer der Militärdiktatur. Begleitband zur Ausstellung im Stadtmuseum Münster, Münster; Rupflin, B., "Kirche in Bewegung. Die Chile-Solidarität der katholischen Studentengemeinde in Münster“ en Baumann, C., Gehrig, S., Bückse, N., (Eds.) (2014). Linksalternatives Milieu und Neue Soziale Bewegungen in den 1970er Jahren, Heidelberg, Universitätsverlag Winter; Camacho Padilla, F., (2010). Una vida para Chile: la solidaridad y la comunidad chilena en Suecia 1970-2010/ EH LIV FÜR CHILE: SOLIDARITETEN MED CHILES FOLK OCH CHILENARE I SVERIGE 1970-2010, Lom Impresiones; Camacho Padilla, F., (2009). Suecia por Chile. Una historia visual del exilio y la solidaridad 1970-1990, Lom Ediciones.

5 Endy, C., "Power and Culture in the West" en: Immermann, R. H. y Goedde, P. (2013). The Oxford Handbook of the Cold War, Oxford, Oxford University Press, p.324.

6 Christiaens, K., Goddeeris, I., Rodríguez, M. (Eds.), European Solidarity...Op.Cit., p.27. 
raron movilizando a la opinión pública europea contra la dictadura chilena. Además de los análisis sobre el rol de la música, se han publicado y se están publicando trabajos sobre el papel del cine y las artes plásticas como conectores y transmisores entre los exiliados y las sociedades europeas ${ }^{7}$.

Este artículo se inscribe en el marco de estos trabajos acerca de las formas culturales que adoptaron los movimientos de solidaridad. Con él, he querido aproximarme a un espacio hasta ahora no trabajado, la feria del libro de Frankfurt de 1976, y analizar cómo y en qué formas esta, en su calidad de evento literario y editorial de relevancia internacional, se articuló como arena política para denunciar las violaciones de derechos humanos en los regímenes dictatoriales del Cono Sur.

En concreto, en este trabajo se plantea una aproximación al ámbito de la literatura como espacio de solidaridad. Para definir más concretamente este "ámbito de la literatura", que a priori puede resultar algo inaprensible, es preciso delinear los espacios, los actores y las prácticas que lo conforman. Entre sus agentes podemos diferenciar editores/as, escritores/as, periodistas, libreros/as, lectores/as, traductores/as y el público lector. Respecto a los espacios donde desarrollan su actividad, encontramos editoriales, redacciones, librerías, universidades, congresos, ferias del libro o cafés, entre otros. Es importante especificar que, al hablar del "ámbito de la literatura" como espacio de acción política, no me refiero necesariamente a la escritura y publicación de textos teóricos o propagandísticos de carácter político, sino a la actuación de estos actores en estos espacios con una intencionalidad política. Utilizando los espacios de la feria como tribunas para pronunciar discursos de denuncia de los crímenes de las dictaduras del Cono Sur y para alentar al compromiso con las fuerzas democráticas de esos países, los participantes politizaron un espacio de intercambio transnacional literario y editorial.

Diferentes escritores y actores del mundo editorial europeo y latinoamericano se posicionaron en estos años como figuras públicas en los movimientos de solidaridad. A través de su participación en iniciativas de denuncia de los regímenes militares del Cono Sur, estos agentes aunaron su actividad literaria con la actividad política en el ejercicio de la palabra escrita y la palabra hablada (participación en eventos públicos, en debates, en revistas, publicación de libros y artículos, etc.). En su libro Entre la pluma y el fusil, la historiadora argentina Claudia Gilman aborda el proceso que lleva al escritor o a la persona de letras a convertirse en intelectual y señala precisamente la actividad en la esfera pública como el elemento clave en esa "conversión": “(...) en los años sesenta, artistas y letrados se apropiaron del espacio público como tribuna desde la cual dirigirse a la sociedad, es decir, se convirtieron en intelectuales" . O, como cita Gilman a Edgar Morin: "El escritor que escribe una novela es un escritor, pero si habla de la tortura en Argelia, es un intelectual"9.

\footnotetext{
7 Algunos ejemplos de estos trabajos son: Fairly, J., "Die Gitarre ist eine Waffe, das Lied ein Kugel. Nueva canción" en Broughton, S. (Ed.) (2000). Welt Musik. Rough Guide, Stuttgart und Weiman; Côté, T. (2011). "Popular Musicians and Their Songs as Threats to National Security. A World Perspective", The Journal of Popular Culture, 44; Oliver, A. A., "Exporting Chile. Film and Literature after 1973", en Nagy-Zekmi, S.; Leiva, F. (Eds.). (2005). Democracy in Chile. The Legacy of September 11, 1973, Brighton \& Portland; Adams, J. (2007). "Exiles, Art, and Political Activism: Fighting the Pinochet Regime from Afar", Journal of Southern African Studies, 33; Simalchik, J. (2006). "The Material Culture of Chilean Exile. A Transnational Dialogue”, Refuge, 23.

8 Gilman, C., (2003). Entre la pluma y el fusil. Debates y dilemas del escritor revolucionario en América Latina, Buenos Aires, Siglo XXI, p. 59.

9 Gilman, C., Entre la pluma... pp. 69-70.
} 
En el caso de los movimientos de solidaridad con Chile, Argentina y Uruguay, hay todo un paisaje por reconstruir en el que escritores y profesionales del mundo literario pasaron a la acción política y adoptaron ese rol de intelectuales. En 1978, Gabriel García Márquez fundó Habeas, organización destinada a la defensa de los Derechos Humanos de los prisioneros políticos latinoamericanos. Entre 1974 y 1976 tuvieron lugar en Roma y en Bruselas las tres sesiones del II Tribunal Russell, concebido para juzgar los crímenes de los regímenes dictatoriales de Chile, Brasil, Uruguay y Bolivia. El escritor argentino Julio Cortázar, el filósofo francés Jean-Paul Sartre o, de nuevo, el colombiano García Márquez se contaron entre los participantes del tribuna $1^{10} .1974$ fue también el año en que parte de estos escritores participaron en una campaña de alcance internacional por la liberación del uruguayo Juan Carlos Onetti. El escritor había sido detenido por la policía del régimen tras haber premiado, como jurado de la revista Marcha, un relato de Nelson Marra que fue calificado por la Junta uruguaya como pornográfico y ofensivo hacia el cuerpo de policía. Tras la detención de Onetti, de Marra y de Mercedes Rein, también miembro del jurado, se desencadenó una campaña en la que personalidades internacionales vinculadas a la política, al periodismo y al mundo editorial y literario pedían su liberación, que tuvo lugar tres meses después. Tras ella, Onetti pudo exiliarse con su mujer en España y el caso redundó en una ola internacional de interés por su obra.

Un último caso para ilustrar la movilización y el paso a la acción política en las escenas literarias latinoamericanas y europeas: en junio 1974, Julio Cortázar escribía una carta al periodista y escritor argentino Juan E. González donde le informaba de los "intensos trabajos" que se estaban llevando a cabo por el pueblo chileno en París. Ese septiembre, contaba Cortázar, aparecería en Francia un libro fruto de la cooperación de un grupo de europeos y latinoamericanos: Chili, le dossier noir, a cuya publicación seguirían ediciones en castellano y en otras lenguas. Además, anunciaba el argentino, estaban inmersos en la organización del Primer Encuentro Cultural Antifascista de Santiago en París, que pretendía ser un homenaje a una iniciativa de Salvador Allende, Pablo Neruda y otros que no llegó a celebrarse en Chile. Ese congreso, contaba Cortázar, "tendrá en París no sólo ese valor de homenaje sino que será una tribuna de combate contra la junta militar de Pinochet y contra todos sus cómplices interiores y exteriores" ${ }^{11}$. Los organizadores del Encuentro aspiraban, -sigue la carta- a través de la puesta en marcha de actividades culturales y de creación artística, a dar lugar a "nuevos enlaces políticos y culturales entre personas y grupos de los más diversos países del globo". Con la celebración del Encuentro querían plantear "un tipo de combate que debe salir de lo ordinario. (...) Grupos de teatro, brigadas de pintura colectiva, conferencias, música, cine, danza, ediciones populares, mesas redondas, a todo eso invitamos y todo eso queremos. Que la junta recoja nuestro desafío si se cree dueña de la verdad, y organice un encuentro al que acudan hombres y mujeres como los que vendrán a decir su palabra o a cantar sus canciones con nosotros"12.

Como objeto de análisis, la feria del libro de Frankfurt ofrece una instancia de enorme relevancia como espacio de discurso y actuación política transnacional en el

10 Guerra Ferreira, L. (2016). "O Tribunal Russell II e a voz da resistência à ditadura militar no Brasil”. Revista Interdisciplinar de Direitos Humanos (2016), v.4, n.2, p.96.

11 Cortázar, J. (2000). Cartas 1969-1983, edición a cargo de Aurora Bernárdez, Alfaguara, Madrid, pp. $1550-1551$.

12 Cortázar,., Cartas..., pp. 1550-1551. 
marco de las iniciativas solidarias por el Cono Sur. A la hora de analizar esta articulación política es importante señalar que la feria no supone un evento con intencionalidad política propia. Los organizadores no se posicionan a favor o en contra de las oposiciones democráticas a los regímenes dictatoriales latinoamericanos. Más bien, con su carácter de evento editorial de resonancia internacional, la feria proporciona un espacio de encuentro relativamente neutral (y de alcance global) que se instrumentaliza por determinados participantes como plataforma de debate y de discurso político.

Aunque la feria de 76 no ha recibido mucha atención en los estudios que trabajan sobre las prácticas culturales de los movimientos de solidaridad, sí que ha sido analizada desde los estudios literarios que abordan la difusión de la literatura latinoamericana en Alemania y en Europa. A diferencia de lo sucedido en otros países europeos, en Alemania Occidental la literatura de América Latina tuvo una recepción relativamente tardía. Los ecos del llamado boom latinoamericano no se hicieron oír en la República Federal hasta finales de los años setenta. En el marco de los estudios literarios, diversos autores y autoras han reconocido el papel central que la feria del libro de Frankfurt de 1976 jugó en la introducción y la recepción de la literatura latinoamericana en el mercado editorial alemán. Sus trabajos se han centrado fundamentalmente en el papel de traductores y lectores como promotores de la literatura de América Latina en las editoriales de la República Federal, así como en los problemas, estrategias y éxitos editoriales a lo largo del proceso ${ }^{13}$.

Este estudio de caso sobre la feria de 1976 se sitúa en la intersección entre, por una parte, los estudios literarios que abordan la llegada y popularización de la literatura latinoamericana a Alemania en la década de los setenta y, por otra parte, los trabajos historiográficos que analizan la emergencia en Europa, en esa misma década, de movimientos de solidaridad y en pro de los derechos humanos tras el eco mediático de los golpes de estado y la instauración de dictaduras militares en el Cono Sur.

A lo largo de esta reconstrucción sobre los discursos y las acciones políticas que tuvieron lugar en la feria de 1976 se analizarán las siguientes cuestiones:

1) ¿De qué formas se politiza el espacio de la feria del libro para promover la solidaridad con la oposición a las dictaduras del Cono Sur?

2) ¿Quiénes son los actores que llevan a cabo esa politización?

3) ¿Qué particularidades presenta el ámbito literario, y en concreto la feria del libro, como espacio de posicionamiento político?

Para indagar acerca de estas preguntas he recurrido al archivo de la Asociación Alemana del Comercio del Libro ${ }^{14}$, en el que están preservados los fondos documentales de la Feria del Libro de Frankfurt. Se trata fundamentalmente de documentos organizativos, de correspondencia o de catálogos. Un papel central como fuente documental para este trabajo lo conforma el archivo de prensa, a través del cual es

13 Algunos ejemplos de estas obras son: Von Römer, D. y Schmidt-Welle, F. (Eds.). (2007) Lateinamerikanische Literatur im deutschsprachigen Raum, Frankfurt am Main, Vervuert; Dill, H. (2009). Die lateinamerikanische Literatur in Deutschland. Bausteine zur Geschichte ihrer Rezeption, Frankfurt am Main, Peter Lang; Müller, G. (Ed.). (2014). Verlag macht Weltliteratur. Lateinamerikanische-deutsche Kulturtransfers zwischen internationalem Literaturbetrieb und Übersetzungspolitik, Berlin, Tranvía y Water Frey.

14 En alemán original: Archiv des Börsenvereins des deutschen Buchhandels 
posible reconstruir muchos de los discursos, de las intervenciones y de las iniciativas políticas que se dieron a lo largo de la feria de 1976.

Este análisis de la dimensión política de la feria del libro de Frankfurt se realizará desde la perspectiva de la Historia transnacional. La elección de este enfoque se debe a la propia naturaleza del espacio de estudio: por una parte, la feria del libro de Frankfurt constituye un espacio de encuentro entre escritores y profesionales del mundo del libro de decenas de países. En el marco de la Guerra Fría, donde el concepto "Telón de acero" ilustra bien las dificultades para cruzar fronteras, la existencia de estos espacios de encuentro provee de raras oportunidades a los individuos de diferentes partes del mundo para reunirse e interactuar: autores, editores y demás profesionales del mundo del libro europeo a ambos lados del Telón de Acero se convierten en intermediarios, en conectores entre los bloques.

Por otra parte, la feria de Frankfurt representaba (y sigue representando) uno de los grandes eventos anuales del calendario editorial y literario internacional. Esto se debe no solo a la cantidad de participantes y la diversidad de nacionalidades presentes, sino especialmente a la escala comercial de la feria, "la más grande de todas", que se mide en la compraventa de derechos de libros (de publicación, de traducción, de comercialización, etc. $)^{15}$. En 1976, participaron en la feria de Frankfurt más de 4000 expositores (de los cuales aproximadamente un millar procedían de la República Federal). Estos asistentes procedían de 67 países diferentes, entre ellos de varios estados latinoamericanos que visitaban por primera vez la feria (Haití, Honduras, Puerto Rico y Panamá). En total, asistieron editores de 16 países latinoamericanos. Varios medios (entre ellos algunos internacionales como El País) destacaron la ausencia de Cuba en el evento, pero el propio director de la feria, Peter Weidhaas, declaró que esta ausencia se debía a problemas organizativos y no a causas políticas. De los más de 4000 expositores, después de la República Federal Alemana, Gran Bretaña fue el país mejor representado (con 478 participantes), seguido por Estados Unidos (con 358). Desde el otro lado del muro, de la Unión Soviética llegaron 78 expositores, de China 50 y de la República Democrática Alemana 46. De España acudieron 184 expositores (no solo editoriales, sino también agencias literarias, empresas, institutos e instituciones culturales). Ediciones Ruedo Ibérico, editorial española de oposición al régimen franquista asentada en París, participaba regularmente en la feria y aparece en el catálogo de 1976 en el grupo de participantes franceses ${ }^{16}$.

Un último aspecto que motiva la elección del paradigma transnacional es la amplia cobertura mediática (tanto de medios nacionales como internacionales), que convirtió a la feria en un escaparate cultural internacional: diferentes medios (para este artículo se ha trabajado esencialmente con y sobre la prensa) cubrieron y reprodujeron los debates, los discursos y las entrevistas en las que participaron autores, traductores o editores. A nivel nacional, es precisamente la confluencia de la intelectualidad alemana e internacional, de miembros de la clase política del país y de la sociedad civil con medios nacionales e internacionales, lo que hacía de la feria un espacio especialmente atractivo para la acción política. Sabine Niemeier, autora de la obra Funktionen der Buchmesse im Wandel, señala la importancia de la medialización del evento, afirmando que es justo esa cobertura mediática y, a través de ella,

\footnotetext{
Owen, L. (2008). Comprar y vender derechos, México DF, Fondo de Cultura Económica, p. 104.

16 Catálogo de la Feria del Libro de 1976.
} 
la potencial resonancia en la sociedad alemana, lo que motivaba a los grupos estudiantiles y de izquierda a planear y llevar a cabo acciones de protesta en la feria ${ }^{17}$.

Por último, conviene detenerse en "la feria" y "los libros" como objetos de estudio: ambos elementos representan lo que, desde la perspectiva transnacional, se interpreta como "conectores no humanos" 18 . Es decir, a través de sus respectivos roles de espacio y de objeto, la feria y los libros permiten la puesta en contacto entre grupos o individuos a través y más allá de las fronteras nacionales. En el caso de la feria, en su inmovilidad, como punto de encuentro al que se desplazan escritores, profesionales del mundo editorial y periodistas de diferentes países. En el caso de los libros, como objetos móviles, que permiten la difusión de contenidos y la puesta en contacto entre personas a escala global sin que estas tengan que desplazarse: En su obra Transnational history. Theory and history, Pierre-Yves Saunier señala el valor como elementos de conexión transnacional de libros y otros textos: "the print media (books, journals, newspapers) and their capacity to move energies across borders"19.

Los propios movimientos de solidaridad con el Cono Sur se constituyen asimismo como fenómenos protagonizados por una compleja red de actores (sociedades civiles, intelectuales, comunidades de exiliados, interlocutores en los países latinoamericanos) que se desplazan o no a través de las fronteras, pero cuyas acciones se proyectan más allá del ámbito nacional. La feria del libro de Frankfurt resulta un escenario de gran interés para analizar los intercambios transnacionales en el marco de estos movimientos de solidaridad, así como para determinar el rol que juegan los espacios y los objetos como canalizadores y detonadores de la acción humana.

\section{Retrospectiva: la politización de la feria del libro de Frankfurt desde finales de los sesenta}

La presencia de reivindicaciones y discursos políticos en la feria del libro de Frankfurt no fue un fenómeno exclusivo del año 1976. Desde la segunda mitad de la década anterior, en el contexto de los crecientes movimientos de protesta estudiantiles en la ciudad, la feria se había convertido en un escenario más en el que estudiantes y grupos izquierdistas llevaban a cabo acciones políticas. Sabine Niemeier señala una doble politización de la feria del libro en el contexto de las transformaciones sociales que se estaban efectuando en la República Federal a finales de los sesenta: por una parte, el evento, de carácter marcadamente internacional (tanto por su magnitud como por la asistencia de invitados y personalidades de la escena literaria de todo el mundo) ofrecía una tribuna de gran resonancia mediática para las protestas políticas. Por otra parte, la autora habla de la creciente crítica por parte de los grupos intelectuales y estudiantiles de izquierda hacia el "consumo pasivo de bienes culturales". La feria del libro de Frankfurt, con sus estrategias comerciales para promocionar el libro como un objeto de consumo más, se convirtió en el objeto de las críticas de estos círculos ${ }^{20}$. Niemeier señala algunos de los casos que, desde finales de los sesenta, caracterizaron la progresiva politización de la feria del libro. Durante la

17 Niemeier, S. (2001). Funktionen der Frankfurter Buchmesse im Wandel. Von den Anfängen bis heute, Wiesbaden, Harrassowitz Verlag, p. 48.

18 Saunier, P. (2013) Transnational History. Theory and History, Nueva York, Palgrave Macmillan, p. 46.

19 Saunier, P., Transnational... p. 46.

20 Niemeier, S., Funktionen ..., p. 46. 
feria de 1967 se produjeron varias protestas contra el stand griego a raíz del golpe de estado que había instaurado una dictadura en el país en abril de ese año. En 1968, tras las manifestaciones y protestas que se habían multiplicado a escala transnacional desde la primavera, tuvieron lugar varias acciones en la feria del libro: el ministro de finanzas del país, Franz Joseph Strauß, solo pudo presentar su libro bajo estricta vigilancia policial, mientras que la concesión del Friedenpreis, el Premio de la Paz, al presidente senegalés Léopold Sédar Senghor, dio lugar a protestas y a la construcción de barricadas en las calles durante la ceremonia de entrega del galardón ${ }^{21}$. Otro fenómeno de finales de la década de los sesenta nos da un nuevo testigo de la emergente politización de la escena literaria en Alemania y, en concreto, de la feria del libro de Frankfurt: la celebración de "Antiferias" o "Contraferias" en la vecina ciudad de Mainz. Con estos eventos, editoriales pequeñas y comprometidas con la publicación de textos políticos pretendían plantear una crítica y una alternativa a la "lógica comercial del bestseller" imperante en la feria Frankfurt y reivindicar el valor social y cultural del libro. La importancia del libro y de las prácticas de lectura en el desarrollo de los círculos izquierdistas y alternativos de la República Federal ha sido detalladamente analizada por Adelheid von Saldern en su estudio sobre los movimientos de lectura en los llamados "largos años sesenta". Von Saldern plantea cómo la lectura de textos críticos se erigió en estos años como una práctica cultural y social que confirió un lenguaje común y un elemento de conexión a los integrantes de las diferentes opciones de izquierda alemanas ${ }^{22}$.

Al analizar los movimientos de solidaridad con Chile que emergen en el país tras el golpe de Estado de Pinochet en 1973, varios estudios han señalado su mayor heterogeneidad ideológica y social como contraste fundamental con la escena de protesta post 1968, protagonizada por grupos estudiantiles y alternativos orientados hacia posiciones de izquierda.

Tras las primeras manifestaciones en septiembre de 1973, las incipientes iniciativas de denuncia del terror de la dictadura militar y en defensa de los derechos humanos de los detenidos por el régimen fueron integrando a sectores muy diversos de la sociedad civil: grupos asociados a la iglesia, sindicatos, intelectuales, estudiantes, etcétera ${ }^{23}$.

En 1976, las protestas e iniciativas por parte de grupos civiles también estuvieron presentes, a pesar de que, en los años anteriores, se había producido una desescalación de las manifestaciones políticas en la feria en comparación con lo ocurrido a finales de los sesenta. La prensa informaba acerca de protestas en diferentes stands: frente al correspondiente a la Unión Soviética, miembros del grupo "Lysti-Blätter" protestaron exigiendo la liberación del líder estudiantil checoslovaco Juri Müller, detenido e incomunicado desde 1972. En torno al stand de la República Democrática Alemana se organizó asimismo una manifestación que protestaba contra las medidas ejercidas por el gobierno del país contra escritores y periodistas a los que se prohibía ejercer su oficio o publicar. El stand de Argentina, por su parte, fue ocupado por grupos de estudiantes de la Universidad de Frankfurt y de la ONG Amnistía Internacio-

$21 \quad$ Niemeier, S., Funktionen... p. 47.

22 Von Saldern, A. (2004). "Markt für Marx. Literaturbetrieb und Lesebewegungen in der Bundesrepublik in den Sechziger- und Siebziger Jahren“. Archiv für Sozialgeschichte, 44, pp. 149-150.

23 Dufner, G. "Professions of political faith. The Solidarity Movement and New Left Imaginaries" en Hansen, J., Helm, C., Reichherzer, F. (Eds.) (2015). Making sense of the Americas. How protest related to America in the 1980s and beyond, Frankfurt am Main, Campus Verlag, p. 166. 
nal que pedían la liberación del también estudiante Klaus Zieschank, arrestado por la policía militar argentina y, según los informes de Amnistía Internacional, torturado en el centro de detención ${ }^{24}$. A pesar de estas iniciativas, la politización de la feria ese año no estuvo protagonizada por la sociedad civil, sino fundamentalmente por los escritores invitados y por la prensa.

\section{América Latina: un continente literario desconocido}

Con el título "América Latina: un continente literario desconocido" 25 , los organizadores de la Feria del Libro de Frankfurt inauguraron, en 1976, un sistema bianual de ejes temáticos o de literaturas invitadas. La idea de los ejes temáticos se había comenzado a barruntar en la primera mitad de los setenta. En 1975, tras la decisión de Sigfred Taubert, que había sido el director de la feria durante dieciocho años, de dejar el cargo, se nombró como nuevo director a Peter Weidhaas. El entonces nuevo director cuenta en $A$ History of the Frankfurt Book Fair que, en el momento en que él asumió el cargo, la feria del libro estaba recibiendo grandes críticas por parte de la prensa y los sectores intelectuales y estudiantiles del país por el rumbo que había tomado en los últimos años, orientado hacia un modelo norteamericano de promoción de best-sellers y a fuertes campañas de marketing y de comercialización ${ }^{26}$. El valor cultural de la actividad editorial y del evento, afirmaban las voces críticas, había quedado desplazado frente a las estrategias destinadas a aumentar los beneficios económicos en el mundo del libro. El gran periódico de Hamburgo, Die Zeit, había llegado a criticar la atmósfera de la feria del libro de Frankfurt afirmando que "quizás era el aspecto comercial o la atmósfera de circo, o posiblemente la combinación de las dos cosas, lo que mantenía al público, autores e incluso editores alejados del evento"27. El propio Gabriel García Márquez, escritor invitado a la edición de 1976 y comprometido públicamente contra los regímenes militares del Cono Sur, se negó por ejemplo a acudir a Frankfurt alegando que los intereses de la feria estaban alineados con los del capitalismo internacional ${ }^{28}$.

Para confrontar a sus críticos y buscar nuevas estrategias se celebró una reunión entre directivos de la feria y una selección de periodistas y redactores. En esta reunión se debatió y se propuso la creación de leitmotivs que introdujeran nuevas tendencias en la feria y dieran respuesta a los desafíos culturales y políticos de la época. Weidhaas habla de que, por una parte, se esperaba que los nuevos leitmotivs "actuaran como alternativa a la mentalidad de bestseller que se había convertido gradualmente en un aspecto predominante en la feria" y "combatieran los problemas de imagen que el evento tenía a los ojos de la intelectualidad de izquierdas del país y de los movimientos estudiantiles que habían emergido desde finales de los sesenta" 29 . La decisión de la dirección de la feria de inaugurar el nuevo sistema de leitmotivs con la literatura latinoamericana como invitada plantea un interrogante inevitable y difícil de responder: ¿Por qué América Latina?

\footnotetext{
"Proteste am Sonntag" en Frankfurter Rundschau, Nr.210, 20 de septiembre de 1976, p.14.

Título en alemán original: «Lateinamerika - ein unbekannter literarischer Kontinent»

Weidhaas, P. (2007). A History of the Frankfurt Book Fair, Durndun Press, p. 193.

Weidhaas, P., A History ..., p. 178. Traducción propia al castellano.

Weidhaas, P., A History ..., p. 195.

Weidhaas, P., A History ..., pp. 193-194.
} 
Ante la ausencia de bibliografía o investigaciones al respecto, la historiadora Katharina Einert hace referencia a las memorias de Weidhaas, donde este afirma que su interés por la literatura latinoamericana surgió en parte a lo largo de un viaje a través de diversos países del continente. El que después sería director de la feria del libro tenía conocimientos de español y pudo acceder esta literatura a pesar de la carencia de traducciones y ediciones alemanas. Asimismo, Weidhaas se muestra consciente del interés que despierta América Latina en el contexto de la creciente politización social y de los movimientos de protesta que surgen a partir de 1968. Años después, en una valoración de la feria de 1976, Weidhaas relataba que las críticas de la prensa y la baja estimación de las editoriales sobre los efectos positivos de participar en la feria cambiaron a partir del año dedicado a la literatura latinoamericana de forma decisiva ${ }^{30}$. Otro aspecto relevante para la elección de la literatura latinoamericana pudo ser que, a mediados de los 70, América Latina constituía literalmente un continente literario desconocido en Alemania Occidental. A pesar del éxito mediático y editorial del llamado Boom latinoamericano en otros países europeos como Francia, Italia o España, la literatura del continente no había conseguido penetrar en los círculos lectores alemanes. Michi Strausfeld, entonces lectora de la editorial Suhrkamp y responsable de la apertura de la editorial a la literatura del continente, describe la situación de la literatura latinoamericana en Alemania a principios de los setenta como desoladora: " $¡ Q u e ́$ páramo, en cambio, el mundo latinoamericano en Alemania! La recepción de grandes obras latinoamericanas durante la década de los sesenta se puede resumir en una palabra: deprimente" 31 .

A finales de la década de los sesenta y principios de los setenta, un pequeño puñado de editores, lectores y traductores habían tratado de introducir algunos títulos latinoamericanos en el mercado editorial alemán. En 1969, desde Cuba, el escritor Hans Magnus Enzensberger había escrito una carta urgente a la editorial Suhrkamp, para la que había trabajado como lector, recomendando la adquisición de los derechos de Cien años de soledad, así como su traducción y comercialización en la República Federal. A pesar de la urgencia, Suhrkamp se encontró con que la editorial Kiepenheuer \& Witsch ya había adquirido la obra ${ }^{32}$. A pesar de ello, escribe Strausfeld, de la novela de García Márquez, publicada en 1970, se vendieron algo más de 9000 ejemplares, "a pesar de unas 50 reseñas positivas, lo cual fue todo un record". Por su parte, "los volúmenes de cuentos de Borges nunca superaron los cinco mil ejemplares", mientras que "los poemas de Neruda fueron leídos por una pequeña élite (...)"33. La feria del libro de Frankfurt de 1976 supuso, según Michi Strausfeld, un punto de inflexión en esta tendencia. La editorial Suhrkamp encabezó el impulso editorial para introducir la literatura latinoamericana contemporánea en el país. En esta época, aparecieron unas cincuenta obras de autores latinoamericanos, de las que 19 fueron traducidas y publicadas por Suhrkamp. Además, cuenta Strausfeld, la editorial publicó diferentes materiales para acercar a la sociedad alemana esa literatura desconoci-

30 Weidhaas, P. (1998) “Impulsgeber. Die Zukunft der Frankfurter Buchmesse”. Börsenblatt Nr. 79, p.78. Citado en Niemeier, Sabine: Funktionen... p. 51.

31 Strausfeld, M. "Cómo viajan los libros: desde América Latina hacia París y Alemania; desde España hacia París y Alemania - semejanzas y diferencias” en Klengel, S. (Ed.) (1997). Contextos, historias y transferencias en los estudios latinoamericanistas europeos. Los casos de Alemania, España y Francia, Frankfurt am Main, Vervuert, p. 32.

32 Wittstock, U. "Wie der Verlag Suhrkamp Lateinamerika entdeckte" en Welt Kultur, 17 de junio de 2010

33 Strausfeld, Michi, "Cómo viajan..." p.32. 
da: "folletos informativos para libreros y críticos y un "periódico" latinoamericano de gran tiraje para los lectores interesados". La lectora señala que esta labor de difusión no estuvo protagonizada solamente por su editorial, sino que "muchas editoriales literarias alemanas, grandes y pequeñas, hicieron un esfuerzo para esta ocasión. Peter Hammer dio a conocer la obra completa de Ernesto Cardenal así como a otros escritores de Nicaragua e hizo una importante labor en pro de aquel país, que pocos años después adquirió fama mundial por su Revolución Sandinista"34.

\section{La politización de la feria del libro de 1976: Voces por el Cono Sur}

Las crónicas de la prensa local y nacional de la época nos permiten reconstruir gran parte de los discursos y debates políticos que acontecieron a lo largo de aquella feria del libro. La politización del evento estuvo esencialmente protagonizada, como apuntábamos, por los escritores asistentes, que habían recibido invitaciones por parte de la dirección para participar de forma activa en las actividades organizadas para aproximar la literatura latinoamericana al público y los medios. Junto a ellos, figuras políticas y del mundo editorial, así como algunos grupos civiles y, fundamentalmente, la prensa, tomaron la palabra para pronunciarse acerca de la situación en los países del Cono Sur. En la ceremonia de apertura, el 15 de septiembre de 1976, tomaron la palabra el alcalde de Frankfurt, Rudi Arndt, el ministro de cooperación económica Egon Bahr y el escritor peruano entonces recién nombrado presidente del PEN Club Internacional, Mario Vargas Llosa. Los tres discursos de apertura estuvieron imbuidos de contenido político, si bien con referencias diferentes: Arndt, alcalde de Frankfurt, habló de la necesidad de superar el desconocimiento y la imagen romantizada de América Latina. Los libros del continente, afirmaba en su intervención, querían hacer visibles la problemática social y cultural de la región al público alemán. El alcalde habló expresamente de la feria como un espacio que debía gestar solidaridad entre los participantes y se refirió al ejercicio concreto de esa solidaridad en la ciudad de Frankfurt, a donde habían ido a parar muchos exiliados chilenos. Arndt terminó su intervención con las siguientes palabras: "La misma hermandad que sentimos hacia las fuerzas democráticas de Chile nos une con todos los latinoamericanos que buscan la libertad, pues todos los pueblos del mundo tenemos aquí una tarea común. Deseo a todos los participantes de la feria del libro que se cumplan sus esperanzas puestas en la palabra impresa" ${ }^{\text {"35 }}$. Por su parte, el ministro de cooperación económica Bahr se refirió a América Latina como una región del Tercer Mundo en lucha por alcanzar su independencia económica en el mercado internacional. "América Latina-sostenía Bahr-es un continente en el que Revolución y ruptura, dictadura y terror coexisten. Sin embargo, la idea de la libertad y el rol del escritor como crítico de la sociedad tienen allí una importante tradición. La mayoría de los autores más relevantes ya ha tomado partido contra la humillación y la opresión, pagando por ello el precio del exilio y la persecución"36. En último lugar tomó la palabra Mario Vargas Llosa. Su caso ilustra bien el hecho de que los autores latinoamericanos

\footnotetext{
Strausfeld, Michi, "Cómo viajan..." p. 33.

35 Rudi Arndt, "Lesende Bürger haben Selbstbewusstsein", discurso de apertura de la feria del libro de Frankfurt, 15 de septiembre de 1976. Presse- und Informationsamt Frankfurt am Main, Archiv des Instituts für Stadtgeschichte, Frankfurt am Main: S3. T12683. Traducción propia al castellano.

36 "Schwerpunkt: Lateinamerika. Eröffnung der Frankfurter Buchmesse" en Frankfurter Allgemeine Zeitung, Feuilleton, 16 de septiembre de 1976, Nr. 207, p. 21. Traducción propia al castellano.
} 
participantes en la feria no representaban un frente unido en lo ideológico, por lo que es importante reconocer la complejidad y la diversidad de sus voces en el terreno político. Vargas Llosa había sido un firme partidario de la Revolución Cubana hasta finales de los sesenta. El llamado "Caso Padilla" (la detención del poeta cubano Heberto Padilla en La Habana bajo acusaciones de contenidos contrarrevolucionarios y la consiguiente publicación por parte de este de una confesión pública en la que aceptaba las acusaciones) provocó la ruptura y el distanciamiento de muchos intelectuales comprometidos con el proceso revolucionario, entre los que Mario Vargas Llosa constituyó un caso especialmente sonado. En su discurso de apertura de la feria de Frankfurt, el autor peruano habló de la necesidad de dar voz a aquellos que, por la pobreza o la represión, estaban condenados al silencio en América Latina. También se pronunció largamente sobre las enormes desigualdades económicas y la miseria imperante en el continente, y señaló como partícipes de la situación tanto al capitalismo como al marxismo internacional, que, según el peruano, aprovechaban su ventaja tecnológica y financiera para contribuir a la explotación continuada de los pueblos latinoamericanos. Vargas Llosa afirmaba en este discurso que ni las dictaduras ni el atraso económico ni la represión en el continente habían conseguido impedir el desarrollo de un espíritu creativo que, en el campo de la literatura, estaba aportando una enorme belleza y originalidad a la cultura contemporánea. A través de estas obras, sostenía el escritor, se expresaban millones de latinoamericanos sin voz.

Junto a esta inauguración, los escritores latinoamericanos, que como decíamos no constituían un bloque homogéneo en lo ideológico, tuvieron otras oportunidades de tomar la palabra. Al comienzo del artículo hablábamos del coloquio organizado en Sprendlingen, cerca de Frankfurt, en el que se conocieron Ricardo Bada y Eduardo Galeano. En este evento, que se celebró unos días antes de la feria, se reunieron los escritores, académicos y periodistas latinoamericanos invitados a la feria con traductores, lectores de editorial, críticos y filólogos alemanes para hablar del carácter de la nueva narrativa latinoamericana, así como de las posibilidades y el futuro de la literatura en el continente. Los temas que se debatieron -la imagen unitaria de la literatura latinoamericana frente a la diversidad cultural y social del continente, lo condescendiente de las representaciones de los indígenas como elementos exóticos o folkóricos, la existencia de un llamado terrorismo literario en los regímenes dictatoriales latinoamericanos, etcétera- muestran hasta qué punto también la literatura se comprendía como un espacio con contenido político. Bada hablaba, en su artículo en recuerdo del escritor uruguayo, acerca de cómo, gracias a la invitación, este y su mujer, que vivían entonces en la Argentina de Videla en una posición muy comprometida, habían podido salir del país y comenzar su exilio europeo. Galeano pronunció esos días algunas de las palabras más expresamente políticas del coloquio contra lo que estaba ocurriendo en Uruguay, en Argentina y en Chile. "América Latina -sostuvo el uruguayo en una de sus intervenciones- está efectuando contribuciones de gran talento y universalidad en el desarrollo de métodos de tortura, técnicas para asesinar personas o ideas y para cultivar el silencio, la impotencia y el miedo"37. Posicionamientos como este desencadenaron varias controversias entre los asistentes. Los debates llegaron a un punto álgido cuando se tematizó la cuestión de si había o no esperanza para la revolución en América Latina y se discutió en concreto la expe-

37 Zimmer, D. E., "Wir: die letzten Entdecker“ en Die Zeit, Feuilleton, Nr. 40, 24 de septiembre de 1976 , p. 36. Traducción propia al castellano de la traducción al alemán. 
riencia cubana. Los participantes alemanes no se mantuvieron al margen de las polémicas políticas: el latinoamericanista de Hamburgo Dieter Reichardt criticó en sus intervenciones los lucrativos negocios que existían entre Alemania y, en sus palabras, "los regímenes de terror en Brasil, Paraguay, Uruguay, Argentina y Chile", así como la doble moral imperante en muchos círculos políticos de la República Federal, que "alzaban la voz cuando un disidente soviético desaparecía en un manicomio, mientras que callaban confusos ante las desapariciones y asesinatos de las Juntas militares en el Cono Sur" ${ }^{38}$. El coloquio de Sprendlingen constituye un acontecimiento interesante para observar la heterogeneidad de las posiciones de escritores y editores, no solo sobre la situación en los países del Cono Sur, sino también sobre la relación entre literatura y política. El curso de las discusiones entre los participantes muestra que estos eventos podían ser un espacio de encuentro, de creación de relaciones y fomento de la solidaridad, pero también de desencuentro, de confrontación y de distanciamiento. El coloquio, de cuyas discusiones e intervenciones se hicieron eco varios periódicos, concluyó con la firma de una petición que se dirigió a la Junta argentina (en la que parte de los participantes no quisieron involucrarse) en favor de los escritores desaparecidos Haroldo Conti y Miguel Ángel Bustos, y del hijo y la nuera del escritor Juan Gelman, que habían sido detenidos como castigo a la voz crítica del padre, que vivía en el exilio desde 1975.

Junto al coloquio, y ya en la feria, los autores invitados tuvieron la oportunidad de tomar la palabra e interaccionar directamente con el público a lo largo de dos tertulias que se organizaron en el recinto y que contaron con la ayuda de un moderador cuya misión era la de actuar de puente entre un público de habla alemana y los escritores de lengua hispana y portuguesa. Muchos medios alemanes criticaron en sus crónicas que las discusiones tomaron la forma de monólogos y que tuvieron un contenido esencialmente político. El 18 de septiembre, el argentino Julio Cortázar habló largo y tendido sobre la ineludible revolución que estaba por hacerse en América Latina. En la misma sesión, el poeta brasileño Thiago de Mello reinvindicó la causa de la Revolución Cubana y Eduardo Galeano habló del rol de la palabra escrita como arma contra el terror y afirmó que "la palabra había vuelto a hacerse peligrosa y que por ello escribir no constituía una pasión inútill" ${ }^{19}$. Estas tertulias no fueron especialmente armónicas: las intervenciones generaron algunas reacciones airadas entre el público y varios editores latinoamericanos abandonaron la sala. Según la prensa, en una de esos conversatorios, el escritor chileno José Donoso, que no había llegado a tomar la palabra, abandonó el estrado exclamando "qué vergüenza, qué vergüenza"

Como ya apuntábamos, es importante destacar el papel de la prensa como caja de resonancia de lo que ocurría en la feria del libro y, en este caso, como medio de difusión de las acciones y los discursos (en el sentido de narrativas) políticos que se dieron en el contexto de la feria. Sin embargo, es también esencial señalar el rol de los medios, y en este caso concreto de la prensa, como actor independiente en esta politización de la feria. No solo durante los días que duró la feria en sí: también en las semanas previas y posteriores se publicaron numerosos reportajes dedicados a la literatura y las realidades de América Latina. Lo novedoso del eje temático para la feria

\footnotetext{
38 Zimmer, D. E., "Wir: die letzten...”p. 36. Traducción propia al castellano.

39 "Ein paar Etüden auf dem Kennerklavier", en Frankfurter Neue Presse, 20. 09. 1976. Traducción propia al castellano.

40 Zimmer, D. E., "Wir, die letzten...“" p. 36. Traducción propia al castellano.
} 
del libro, y dentro de ello lo novedoso de la literatura latinoamericana para la sociedad alemana, recibieron gran atención por parte de los periodistas. En la práctica totalidad de estos artículos, los autores no dejan de expresarse (en tonos más o menos críticos) sobre la realidad política en los países latinoamericanos (los recientes golpes de estado, las violaciones de Derechos Humanos, pero también la pobreza y la dimensión de las desigualdades sociales). Es difícil disociar lo literario y lo político en muchos de estos textos. Por lo general, la literatura latinoamericana fue presentada, por una parte, como un conjunto de voces originales y de gran calidad literaria que habían ganado por derecho su lugar en la cultura contemporánea, $\mathrm{y}$, al mismo tiempo, como una puerta a comprender y enunciar la situación sociopolítica de los países del continente. "Una gran parte de la literatura latinoamericana es, por el contrario, extrovertida, llena de historias y de Historia." -escribía Dieter E. Zimmer en el Feuilleton del periódico Die Zeit- "Es política, sin por ello hacer concesiones estéticas. Ciertamente no le falta modernidad, porque proviene de una sociedad con otro Zeitgefühl, en el que hoy conviven la Edad de Piedra y la Industrialización. No está confrontada con una realidad exhaustivamente formulada, sino con una que espera ser nombrada; sobre esta literatura pesa una esperanza diferente: debe ayudar al subcontinente a encontrar su identidad, debe hablar de la Verdad, allí donde oficialmente impera la Mentira" ${ }^{41}$. El 24 de septiembre, en el mismo periódico, el periodista Rudolf Walter Leonhard escribía que una feria de esas características tenía que ser necesariamente política: "La lección de 1968/1969 se ha convertido en el programa de la feria. La propia dirección ha hecho de "América Latina" el eje temático y, donde la literatura latinoamericana está presente, la política lo está también" ${ }^{2}$. Otro artículo de esa semana señalaba que no sólo América Latina, sino el terror, se había convertido en el tema de la feria del libro. En la exposición sobre literatura latinoamericana organizada en uno de los pabellones del recinto -continuaba-, los libros expuestos en las vitrinas eran más que objetos bibliográficos: estaban presentados como portadores de opinión ${ }^{43}$.

Durante los días de la feria, los artículos y las crónicas se intensificaron y cubrieron las intervenciones de los participantes y del público. Como veíamos en el último ejemplo, junto a los debates que tuvieron lugar en la feria, la prensa también se hizo eco de una serie de eventos y actividades culturales concebidas para ofrecer al público y a los expositores un trasfondo más amplio de la problemática cultural y social de América Latina: el domingo 19 de septiembre se organizó un concierto dedicado a Chile donde se puso música a poemas de Pablo Neruda. En un centro cívico de la ciudad, la Asociación de Editores Socialistas y Democráticos celebró al día siguiente un nuevo evento bajo el título "Nuestro canto no se acallará", en el que participaron Juan Miranda y el grupo los Andariegos y se leyeron nuevamente algunos textos de Neruda. Asimismo, durante esa semana el cine comunal de la ciudad ofreció un ciclo de cine latinoamericano bajo el tema de "El Cine Perseguido". Se pudieron ver títulos chilenos y colombianos como "La batalla de Chile", de Patricio Guzmán (19731974), "A los pueblos del mundo" (1975), "Los hijos del subdesarrollo”, "¿Qué es la democracia?", de Carlos Álvarez (1971), "Campesinos" (1975) y “Chircales" (1973).

${ }^{41}$ Zimmer, D. E., "Wir, die letzten..." p. 36. Traducción propia al castellano.

42 Leonhard, R. W., "Nüchterne Nostalgie: eine Kurzgeschichte der Frankfurter Buchmesse 1949 bis 1976 ” en Die Zeit Feuilleton, Nr. 40, 24 de septiembre de 1976. Traducción propia al castellano.

43 "Auch Terror als Thema" en Frankfurter Rundschau, Nr. 210, 20 de septiembre de 1976, p. 14. Traducción propia al castellano. 


\section{Conclusiones}

La cuestión, tan difícil de estimar, del impacto social se abre en este punto. Las fuentes con las que he trabajado permiten fundamentalmente interpretar y reconstruir la intencionalidad y los discursos de autores, periodistas y personalidades del mundo político y editorial que, a lo largo de la feria, se pronunciaron políticamente acerca de la situación bajo las dictaduras latinoamericanas. Una crítica que se repite con frecuencia en los artículos periodísticos de esas semanas de 1976 es la de los problemas de comunicación entre los autores, mayoritariamente de habla hispana, y el público alemán. Solo con esto resulta difícil medir el impacto de estos pronunciamientos sobre la sociedad alemana e, incluso, sobre la escena literaria y editorial nacional e internacional. En la obra The Diffusion of Social Movements, los autores tratan de delinear las formas en que se produce la difusión de ideas y comportamientos, así como el impacto de esa difusión. En su análisis del fenómeno, reconocen su naturaleza escurridiza pero establecen, como condición necesaria para que esa difusión tenga lugar, la actuación política: "(...) diffusion may be driven by identifiable mechanisms, but it is far from being a mechanical process. It is heavily conditioned by political agency, and it almost always involves the interaction between formal and informal institutions." ${ }^{44}$ Este trabajo ha tratado de abordar precisamente esa political agency, la performance política de los participantes en la feria. A pesar de que la cuestión del impacto permanece abierta, hay que referir que, en los años posteriores a la feria del 76 se pusieron en marcha en la Alemania federal algunas iniciativas en las que se aprecia esa confluencia entre lo literario y la intencionalidad política. En 1980, por ejemplo, se creó LitProm, una organización destinada a promover la literatura de África, Asia y América Latina en el país. La asociación se fundó en Frankfurt en 1980 y ha continuado trabajando hasta la actualidad para establecer contactos con escritores y editores de estos continentes y para traducir y dar a conocer sus corrientes literarias en Alemania. LitProm se fundó por profesionales del mundo editorial y literario, por asociaciones de ayuda al desarrollo y por la feria de Frankfurt. En su página web, describen su actividad como una forma de combatir la ignorancia y los estereotipos en torno a África, Asia y América Latina en Alemania, así como de establecer un intercambio cultural a través de la literatura ${ }^{45}$.

Por otra parte, en el marco de los festivales de las Culturas del Mundo que comenzaron a celebrarse en Berlín a partir de 1979, tuvo lugar la celebración del festival Horizonte 82, dedicado a la cultura de América Latina. En este evento la revolución sandinista y las denuncias contra el terror en el Cono Sur estuvieron muy presentes a través de las exposiciones, los conciertos, las lecturas y el resto de actividades orientadas a acercar, a través de lo cultural, la realidad latinoamericana a los asistentes.

Por último, tres meses después de la feria, la dirección de la misma publicó los resultados y la valoración de la encuesta hecha a los editores participantes: según estos resultados, el 54\% de los expositores consideraron la introducción de un eje temático en la feria, en este caso la literatura latinoamericana, como un elemento positivo. Un seis por ciento de los participantes declaraban haber llegado a acuerdos y contratos concretos con los invitados latinoamericanos. El director de la feria, Peter Weidhaas valoraba el

\footnotetext{
44 Kolins Givan, R., Roberts, K. M., Soule, S. A. (Eds.). (2010) The Diffusion of Social Movements. Actors, Mechanisms and Political Effects, Cambridge, Cambridge University Press, p. 3.

45 http://www.litprom.de/about-us/ Consultado el 13 de marzo de 2018.
} 
curso comercial de la feria como "de un optimismo moderado", y el sistema de literaturas invitadas o ejes temáticos quedó establecido, en un principio cada dos años, a partir de entonces. Al pensar en los ecos políticos, es interesante observar los temas elegidos en las ediciones posteriores: en 1978, la feria abrió con el lema "Los niños y el libro". La periodista Renate Zeis señalaba que se esperaba que, en esa edición, la feria haría hincapié en la necesidad de fomentar la lectura entre niños y jóvenes hijos de los trabajadores extranjeros en el país, así como de aumentar la presencia del "Tercer Mundo" en la literatura infantil y juvenil ${ }^{46}$. En 1980, el año de la fundación de LitProm, la elección recayó sobre la literatura africana. En 1982, el eje temático fue la literatura religiosa y, en 1984, la feria estuvo dedicada a la obra de George Orwell. A partir de 1986, con la elección de la India, los ejes temáticos se convirtieron en países invitados.

La feria de 1976, como centro gravitatorio de la escena editorial y literaria internacional, posibilitó el encuentro, el diálogo y la discusión sobre la literatura latinoamericana contemporánea. De la mano de la literatura, de los que la escribían, la traducían y la publicaban, llegaron a la feria las palabras políticas. 1976 fue, en palabras del catedrático de literatura Hans-Otto Dill, el "año mágico latinoamericano" en Alemania. Fue también el año en que, meses antes de la feria, la junta militar encabezada por el general Videla tomaba el poder en Argentina e instauraba una nueva dictadura en la región. En este contexto, la feria del libro de Frankfurt, en su condición de espacio cultural y de encuentro a escala global (y en el marco de las dificultades de movimiento de la Guerra Fría), se articuló como una plataforma propicia para la difusión de discursos políticos. Escritores, periodistas o profesionales del mundo del libro adoptaron el rol clásico del intelectual, el de la intervención en la esfera pública, para expresar una urgencia concreta: la de alentar, desde los espacios privilegiados que ofrecían arte y la literatura, a la solidaridad con la oposición a las dictaduras latinoamericanas. Así lo afirmó Julio Cortázar en su intervención en una de las mesas redondas de la feria: "la palabra es mi única arma porque no puedo usar otras" ${ }^{\prime 4}$.

\section{Referencias bibliográficas y fuentes}

Adams, J. (2013). "Exiles, Art, and Political Activism: Fighting the Pinochet Regime from Afar". Journal of Refugee Studies, 26.

Ayén, X. (2013). Aquellos años del boom. García Márquez, Vargas Llosa y el grupo de amigos que lo cambiaron todo, Barcelona, RBA.

Bada, R. (2015). "El chanchito con la margarita en el hocico. Una memoria de Eduardo Galeano", https://www.nexos.com.mx/?p=24648 Consultado el 13.04.2015.

Baumann, C., Gehrig, S., Bückse, N. (Eds.) (2014). Linksalternatives Milieu und Neue Soziale Bewegungen in den 1970er Jahren, Heidelberg, Universitätsverlag Winter.

Bosshard, M. T. (Ed.) (2015). Buchmarkt, Buchindustrie und Buchmessen in Deutschland, Spanien und Lateinamerika, Berlin/Münster, LIT Verlag.

Christiaens, K., Goddeeris, I., Rodríguez, M. (Eds.). (2014) European Solidarity with Chile 1970s-1980s, Frankfurt am Main, Peter Lang.

Cortázar, J. (1984) Argentina. Años de alambradas culturales, Barcelona, Muchnik.

46 Zeis, R., artículo en el Frankfurter Allgemeine Zeitung, 8 de diciembre de 1976.

47 "Ein paar Etüden..." 
Cortázar, J. (2000) Cartas 1969-1983, edición a cargo de Aurora Bernárdez, Madrid, Alfaguara.

Dill, H. (2009). Die lateinamerikanische Literatur in Deutschland. Bausteine zur Geschichte ihrer Rezeption, Frankfurt am Main, Peter Lang.

Gilman, C. (2003). Entre la pluma y el fusil. Debates y dilemas del escritor revolucionario en América Latina, Buenos Aires, Siglo XXI.

Hammond, A. (2006). Cold War Literature. Writing the global conflict, Londres/Nueva York, Routledge.

Hansen, J., Helm, C., Reichherzer, F. (Eds.) (2015). Making sense of the Americas. How protest related to America in the 1980s and beyond, Frankfurt am Main, Campus Verlag.

Klengel, S. (Ed.) (1997). Contextos, historias y transferencias en los estudios latinoamericanistas europeos. Los casos de Alemania, España y Francia, Frankfurt am Main, Vervuert.

Kolins Givan, R., Roberts, K. M., Soule, S. A. (Eds.) (2010). The Diffusion of Social Movements. Actors, Mechanisms and Political Effects, Cambridge, Cambridge University Press.

Müller, G. (Ed.) (2014). Verlag macht Weltiteratur. Lateinamerikanische-deutsche Kulturtransfers zwischen internationalem Literaturbetrieb und Übersetzungspolitik, Berlin, Tranvía y Water Frey.

Niemeier, S. (2001). Funktionen der Frankfurter Buchmesse im Wandel. Von den Anfängen bis heute, Wiesbaden, Harrassowitz Verlag.

Owen, L. (2008). Comprar y vender derechos, México DF, Fondo de Cultura Económica.

Pohl, B. (2003). Bücher ohne Grenzen. Der Verlag Seix Barral und die Vermittlung lateinamerikanischer Erzählliteratur im Spanien des Franquismus, Frankfurt am Main, Vervuert.

Reichardt, S. (2014). Authentizität und Gemeinschaft. Linksalternatives Leben in den siebziger und frühen achtziger Jahren, Berlin, Suhrkamp.

Von Römer, D. von y Schmidt-Welle, F. (Eds.) (2007). Lateinamerikanische Literatur im deutschsprachigen Raum, Frankfurt am Main, Vervuert.

Von Saldern, A. (2004). "Markt für Marx. Literaturbetrieb und Lesebewegungen in der Bundesrepublik in den Sechziger- und Siebzigerjahren". Archiv für Sozialgeschichte 44, pp. 149-180.

Saunier, P. (2013). Transnational history. Theory and history, Nueva York, Palgrave Macmillan.

Weidhaas, P. (2007). A History of the Frankfurt Book Fair, Toronto, Durndun Press.

Wiese,C.(1992).DiehispanoamerikanischenBoom-RomaneinDeutschland:Literaturvermittlung, Buchmarkt und Rezeption, Frankfurt am Main, Vervuert.

Wittstock, U. (2010) "Wie der Suhrkamp Verlag Lateinamerika entdeckte“ en Welt.

\section{Selección de artículos del archivo de prensa del Börseverein des deutschen Buchhandels ${ }^{48}$}

“Auch Terror als Thema” en Frankfurter Rundschau, Nr. 210, 20 de septiembre de 1976, p. 14.

48 En algunos casos se trata de recortes de páginas de periódicos, por los que no aparece la página exacta. En el resto de los casos se ha añadido el número de página. Cuando no se especifica el autor es debido a que el artículo no aparecía firmado. 
"Ein paar Etüden auf dem Kennerklavier", en Frankfurter Neue Presse, 20. 09. 1976.

Leonhard, Rudolf Walter: "Nüchterne Nostalgie: eine Kurzgeschichte der Frankfurter Buchmesse 1949 bis 1976" en Die Zeit Feuilleton, Nr. 40, 24 de septiembre de 1976. Traducción propia al castellano.

"Proteste am Sonntag" en Frankfurter Rundschau, Nr.210, 20 de septiembre de 1976, p.14.

"Schwerpunkt: Lateinamerika. Eröffnung der Frankfurter Buchmesse" en Frankfurter Allgemeine Zeitung, Feuilleton, 16 de septiembre de 1976, Nr. 207, p. 21.

Zimmer, Dieter E.: "Wir: die letzten Entdecker" en Die Zeit, Feuilleton, Nr. 40, 24 de septiembre de 1976, p. 36. 